\title{
Alternatives of synthetic chemicals - chemicals derived from foods and related materials
}

\author{
SUSANTA LAHIRI ${ }^{1,2}$ \\ 1Saha Institute of Nuclear Physics, India, \\ ${ }^{2}$ Homi Bhabha National Institute, India \\ susanta.lahiri@saha.ac.in
}

\begin{abstract}
Summary
Foods are composed of numerous chemicals, each of them work individually or synergistically inside the living organism for a specific reaction supporting the life processes. To date, the efficacy of these chemicals in industrial processes has been explored to a limited extent. In fact, chemicals derived from food have great potential to be used in multi-disciplinary sciences and in numerous applications.

Synthetic chemicals might be replaced by the natural resources in the future which will also reduce the environmental impact of hazardous and toxic chemicals. The present article gathers a few examples of chemicals derived from food or related materials and shows how worthy they are in various fields, ranging from radiopharmaceuticals to alternative mining of precious metals. In a nutshell, the article puts forward a few simple ways through which research may adjoin the greener mandates and help in maintaining the sustainability of our environment.
\end{abstract}

Keywords: foods, food supplements, proteins, environmentally benign reagents, bio-accumulation

\section{Introduction}

Green Chemistry is the youngest branch of science, which took birth in 1990 from an US environmental law stating that the first choice for preventing pollution is to design industrial processes that do not lead to waste production. In last three decades tremendous development was observed in the field of green chemistry. It took its shape originally with twelve mandatory principles followed by another twelve additional principles. The green chemistry emphasizes on reducing the use of chemicals in chemical processes and to use environmentally benign reagents and solvents. For example, in green synthesis, some of the solvents like water, ethanol, methanol, acetone, 2-propanol, 1-propanol, ethyl acetate, 1-butanol, etc., are designated as safe solvents. The usable solvents are cyclohexane, heptane, acetic acid, xylene, acetonitrile, etc., while benzene, heptane, di-ethyl ether, chloroform, etc., are designated as 
undesirable solvents. Similarly, some reagents like long chain polymers, etc., are viewed as environmental friendly reagent.

For last two decades, we have practiced green chemistry mandates and used environmentally benign reagents like calcium alginate hydrogel beads (Nayak and Lahiri, 2006), iron-doped calcium alginate beads (Banerjee et al., 2007), ionic liquids (Ghosh et al., 2013), polyethylene glycols (PEG) (Roy and Lahiri, 2006), sodium malonate (Dutta et al., 2014), Triton X-114 (Mandal and Lahiri, 2013), poly(N-vinyl pyrrolidone) (PVP) (Lahiri and Sarkar, 2007), etc., in various separation processes.

However, even while using the environmentally benign reagents in chemical processes, it is to be kept in mind that there are energy requirements, might be in lesser extent, for manufacturing these ecocompatible chemicals. Sometimes, environmentally harmful reagents are part of the batch processes in the production cycle of these chemicals. In the green synthesis route atom economy are maintained highly but not necessarily fully balanced and sometime by-products essentially become the burden of green chemists.

Therefore, it is of utmost necessary to follow the nature's processes, where hundred thousand of chemicals are being efficiently produced using ambient temperature and pressure. The natural by-products initiate other important chemical or biochemical reactions to support the life on Earth. Understanding natural chemical processes or in short Nature Based Chemistry (NBC) should be prime thrust in future.

In last ten years we have identified some natural chemicals mainly derived from food products or directly used some lower plant species in high end separation science and technology, which have been categorically described below.

\section{Preservation of orange peel - for costly chemical hesperidin}

Hesperidin, a bioflavonoid, was isolated from orange peel and proposed as radiopharmaceutical-ligand with positron emission tomography (PET) isotopes. For example, ${ }^{89} \mathrm{Zr}$ is well suited for immuno-PET, tracking and quantification of monoclonal antibodies (mAbs). Apart from the use as diagnostic radionuclide, both $88,89 \mathrm{Zr}$ may be suitable therapeutic radionuclide in cellular level, as both of these radionuclides have high intensity Auger electrons. One of the disadvantages of targeted radionuclide therapy is generation of free radicals by the emitted radiations via hydrolysis of body fluids. This would be especially more prominent when targeted dose has to be delivered at DNA level. For the first time ${ }^{88} \mathrm{Zr}$-hesperidin was proposed as radiopharmaceutical for targeted therapy, which may act not only as a potential therapeutic agent and but also as free radical scavenger in the cellular level. We have also developed method for separation of no-carrier-added radioisotope of ${ }^{89} \mathrm{Zr}$ 
from yttrium target using hesperidin as separation reagent, which was isolated from orange peel (Ghosh et al., 2017). At lower acid concentration, $\left(10^{-4} \mathrm{M} \mathrm{HCl}\right)$, high separation between $\mathrm{Zr}$ radionuclides and bulk $\mathrm{Y}$ was achieved and most of the $\mathrm{Zr}$ radionuclides were extracted by hesperidin with $<1 \%$ contamination from $\mathrm{Y}$.

Extraction of gold by different algae - an alternative

Extensive research to understand the role and application of biological entities not only for the environmental remediation of toxic metals but also for commercial extraction of precious and industrial metals is prevalent. Commercial extractions are predicted to be low-cost, lowenergy and eco-friendly. We have studied the feasibility of commercial extraction of gold by some algal genera (Table 1), and also suggested recovery reagents of accumulated gold.

Table 1. A list of species utilized as bio-reagents for Au extraction under different experimental conditions

\begin{tabular}{|c|c|c|c|}
\hline Species \& Family & $\begin{array}{c}\text { Experimental } \\
\text { variations }\end{array}$ & $\begin{array}{c}\text { Best condition and } \\
\text { observation }\end{array}$ & $\begin{array}{c}\text { Desorption } \\
\text { reagent }\end{array}$ \\
\hline $\begin{array}{l}\text { Nitzschia obtusa } \\
\text { (Bacillariophyceae) }\end{array}$ & $\begin{array}{c}\mathrm{pH}: 3,7 \\
\text { Exposure time: } \\
0.5,1,3,24 \mathrm{~h} \\
\text { Au concentration: } \\
0.1,1,5 \mathrm{ppm}\end{array}$ & $\begin{array}{c}\mathrm{pH}=3 \\
\sim 73 \% \text { accumulation } \\
\text { after } 24 \mathrm{~h} \\
\text { Maximum accummulation } \\
\text { for } 0.1 \text { and } 1 \mathrm{ppm} \mathrm{Au} \\
\text { concentration at pH } 3\end{array}$ & $\begin{array}{c}\text { Concentrated } \\
\mathrm{HNO}_{3}\end{array}$ \\
\hline $\begin{array}{l}\text { Navicula minima } \\
\text { (Bacillariophyceae) }\end{array}$ & $\begin{array}{c}\mathrm{pH}: 3,7,8 \\
\text { Exposure time: } \\
0.5,1,3,24 \mathrm{~h} \\
\text { Au concentration: } \\
0.1,1,5 \mathrm{ppm}\end{array}$ & $\begin{array}{c}\mathrm{pH}=7 \\
\sim 85 \% \text { accumulation } \\
\text { after } 24 \mathrm{~h} \\
\text { Maximum accummulation } \\
\text { for } 0.1 \mathrm{ppm} \mathrm{Au} \\
\text { concentration at } \mathrm{pH} 7\end{array}$ & $\begin{array}{c}\text { Concentrated } \\
\mathrm{HNO}_{3}\end{array}$ \\
\hline $\begin{array}{l}\text { Rhizoclonium } \\
\text { riparium } \\
\text { (Chlorophyceae) }\end{array}$ & $\begin{array}{c}\text { pH: } 6,7,8 \\
\text { Exposure time: } \\
0.5,1,3,24,48,72,96 \mathrm{~h} \\
\text { Au concentration: } \\
0.1,1,5 \text { ppm }\end{array}$ & $\begin{array}{c}\mathrm{pH}=8 \\
\text { Maximum accummulation } \\
\text { after } 96 \mathrm{~h} \\
\sim 79 \% \text { accummulation for } \\
5 \text { ppm Au concentration at } \\
\text { pH } 8\end{array}$ & $\begin{array}{c}\text { Concentrated } \\
\mathrm{HNO}_{3}\end{array}$ \\
\hline $\begin{array}{l}\text { Lyngbya majuscula } \\
\text { (Cyanophyceae) }\end{array}$ & pH: $6,7,8$ & $\begin{array}{c}\mathrm{pH}=6 \\
\sim 96.4 \% \text { accumulation } \\
\text { after } 72 \mathrm{~h}\end{array}$ & \\
\hline $\begin{array}{l}\text { Spirulina subsalsa } \\
\text { (Cyanophyceae) } \\
\text { Rhizoclonium } \\
\text { hieroglyphicum } \\
\text { (Chlorophyceae) }\end{array}$ & $\begin{array}{l}\text { Exposure time: } \\
\text { Rapid monitoring till } \\
1 \mathrm{~h} \text { at } 10 \text { min interval, } \\
\text { then } 3,24,48,72 \mathrm{~h}\end{array}$ & $\begin{array}{c}\mathrm{pH}=6 \\
\sim 86.4 \% \text { accumulation } \\
\text { after } 72 \mathrm{~h} \\
\mathrm{pH}=7 \\
\sim 77 \% \text { accumulation } \\
\text { after } 24 \mathrm{~h} \\
\end{array}$ & Thiourea \\
\hline
\end{tabular}


Diatoms are one of the most common primary producer organism amongst the numerous algal species prevalent in both marine and fresh water ecosystems and playing a direct role in the food chain. It was also inferred that the gold accumulation by diatom was mainly due to passive adsorption by biosilica (siliceous frustules of dead diatom cells).

The process of metal accumulation by biological species may take place via metabolism-independent "adsorption" (biosorption) at the cell surface or through metabolism-dependent internal "absorption" inside the organelles or cytoplasmic ligands and structures. Inorganic ions, nonessential elements, etc., are generally adsorbed via rapid metabolismindependent mechanism. Both the living diatom cells and diatom frustules (siliceous covering of the cell) obtained after killing the diatom cells with chromic acid solution, were tested for their gold removal ability under in vitro condition. Their absorption kinetics at different $\mathrm{pH}$ and different substrate concentrations, also their intra cellular compounds like proteins and fats were investigated for measuring accumulated $\mathrm{Au}$ within these components. N. minima cells showed a rapid uptake indicating that gold accumulation is a metabolism independent process and is restricted to the cell surface. Au was also accumulated in high quantity (from $5 \mathrm{ppm}$ Au solution) by the frustules through a rapid adsorption process further supporting the idea that gold accumulation is a metabolism independent process and an outer cell phenomenon. The amount of Au thus accumulated can also be recovered from diatom biomass as well as $\mathrm{Au}$ treated frustules by treating with concentrated $\mathrm{HNO}_{3}$. In fact, the siliceous cell wall of diatom cells or frustules play the major role in metal accumulation processes (Chakraborty et al., 2006).

The results are significant because in natural lakes and seas diatoms bloom twice a year. However, dead diatom frustules are available all over the year, which can also be used for detection and separation of precious metals in natural acidic lakes, rivers or industrial wastes.

Apart from diatoms, green alga Rhizoclonium riparium was used to study the pre-concentration of gold present in trace amounts. We also tried to understand the binding mechanism of gold on Rhizoclonium by isolating fat, protein and carbohydrate parts of the algal biomass and measuring $\mathrm{Au}$ accumulation in these components. It was found that almost the entire gold was attached to the cellulose fibers, and only a small portion was accumulated in protein fraction (Nayak et al., 2006).

Accumulation of gold on Rhizoclonium was found to be almost $\mathrm{pH}$ independent, marginally better at $\mathrm{pH}$ 8. For desorption, conc. $\mathrm{HNO}_{3}$ was used to back extract the accumulated gold in the aqueous solution.

We have also investigated the gold extraction properties of two cyanobacteria, Lyngbya majuscula, Spirulina subsalsa and one eukaryotic 
alga Rhizoclonium hieroglyphicum. Initially quick metabolic independent binding of $\mathrm{Au}$ to the algal biomass was observed followed by active accumulation. The most interesting part is that a biotransformation of $\mathrm{Au}(\mathrm{III})$ to $\mathrm{Au}(0)$ was also observed. TEM studies of L. majuscula biomass exposed in $\mathrm{HAuCl}_{4}$ solution confirmed $<20$-nm-sized gold nanoparticles in both inside as well as on the surface of the cell. The initial step involves trapping of the metal ions on the cell surface possibly via electrostatic interaction between the ions and negatively charged carboxylate groups present in the cell surface. Probably, the reduction of gold particles occurs in the presence of cellular reductases. Similar experiment was carried out with the heat-killed biomass. Interestingly, the heat- killed biomass could not transform $\mathrm{Au}(\mathrm{III})$ to $\mathrm{Au}(0)$, suggesting that the reduction process is an internal cellular phenomena. Thiourea was found to be the best washing reagent for all the algal genera, recovering $>90$ 100\% gold from algal phases (Chakraborty et al., 2009).

The results indicate that live algal biomass may be a viable cost effective means for phytomining of gold alternative to the hazardous reclamation of precious metal gold from industrial wastes. Algae are the promising bioreagents for the fabrication of gold nanoparticles, and an emerging field of nano-biotechnology.

Life supporting ${ }^{201} \mathrm{Tl}$ radionuclide - algae can accumulate it in pure form The radionuclides ${ }^{199,201} \mathrm{Tl}$ are used for myocardial perfusion imaging and evaluation of coronary artery disease. These radionuclides are always produced with lead and mercury radionuclides. Therefore, in vivo application of these radionuclides demands high purity, free from $\mathrm{Pb}$ and $\mathrm{Hg}$ radionuclides. There are few chemical separation techniques involving carcinogenic compounds including organic solvents. It is true that heavy metal accumulation by bio-organisms and even by algae was studied many years ago. However until now not many intentional separations have been carried out, especially by algae. We have demonstrated that algal species, Rhizoclonium hieroglyphicum can be efficiently used as natural bio-reagents in the separation of thallium radionuclides. Algal treatment with an aqueous solution at $\mathrm{pH} 8$ containing mixture of radionuclides of $\mathrm{Pb}, \mathrm{Hg}$ and $\mathrm{Tl}$ shows that Rhizoclonium accumulates $\mathrm{Hg}$ and $\mathrm{Pb}$ leaving only thallium radionuclides in the aqueous phase. The separation factors were of the order of 6000, no less than conventional techniques or even better. The accumulation of $\mathrm{Pb}$ at basic $\mathrm{pH}$ by Rhizoclonium was due to an adsorption process via extracellular or cell wall ligands. This was also supported by the fact that on washing the algal biomass with dilute acid, EDTA or even with distilled water, its metal content got drastically reduced. On the other hand, $\mathrm{Hg}$ accumulation might be an internal process, i.e., adsorption by 
cell wall surface ligands as it was difficult to remove $\mathrm{Hg}$ even by EDTA solution.

Thus the selectivity of various algae towards different metals in sorption and desorption processes may be exploited in the separation of these metals from a mixture of them (Nayak et al., 2002).

Piperine, an alkaloid from fruits of piper nigrum - excellent specific reagent for gold

There are some constrains in the use of living organisms, viz. availability throughout the years, contamination free culture, unialgal culture (for alga), which make them sometime disadvantageous or not user friendly.

Therefore biomolecules which are derived from living systems, such as proteins, alkaloids, biopolymers, etc., may prove beneficial for regular use. Plant bio-reagents are of great interest over the synthetic chemical reagents, as isolation of these natural plant bio-molecules cause less environmental pollution than the synthesis of chemical reagents. In literature there are scanty of reports available on interaction between a metal and an alkaloid derived from plant products. We have identified and isolated piperine, an alkaloid derived from the fruits of Piper nigrum (commonly known as black pepper), as specific bioreagent for gold extraction. Even the fruit Piper nigrum, itself can act as an efficient exchanger for gold. The accumulation of gold by these bio-reagents are $\mathrm{pH}$ dependent and maximum accumulation occurs at $1 \mathrm{M} \mathrm{HCl}$ concentration (Ghosh and Lahiri, 2007). Though there are number of donor sites in piperine, but probably the enone group can form a sandwich type of complex with gold. The developed method may also be useful for recovery of gold from the waste effluent.

Black pepper also shows bioaccumulation property for chromium. Accumulation of $\mathrm{Cr}(\mathrm{VI})$ by black pepper is always negligible throughout the $\mathrm{pH}$ range of $1-7$, however at $\mathrm{pH} 4$, black pepper considerably accumulates $\mathrm{Cr}(\mathrm{III})$. Interestingly, it was found unlike gold accumulation, piperine is not responsible for accumulation of $\mathrm{Cr}(\mathrm{III})$. The other constituents of black pepper like gum or terpenoid might be responsible for bio-accumulation of $\mathrm{Cr}$ (III) (Nayak et al., 2009). It was also found that the maximum capacity of $\mathrm{Cr}(\mathrm{III})$ adsorption is $\sim 57$ ppm per $0.1 \mathrm{~g}$ of black pepper. The accumulated $\mathrm{Cr}$ (III) strongly bound with black pepper in such a way that it could not be desorbed even by EDTA.

Metal-protein interaction - a tool to study molecular make up

Interaction of albumin with clinically important radioisotopes like, ${ }^{61} \mathrm{Cu}$, ${ }^{66-68} \mathrm{Ga},{ }^{62,63} \mathrm{Zn},{ }^{66,67,69} \mathrm{Ge},{ }^{71,72} \mathrm{As},{ }^{73} \mathrm{Se},{ }^{197 m} \mathrm{Hg},{ }^{199-201} \mathrm{Tl},{ }^{199-200} \mathrm{~Pb},{ }^{204} \mathrm{~Pb},{ }^{204} \mathrm{Bi}$, 204,205 Po were studied in multi-elemental environment. In nature, numbers of elements are present together, rather than one single element; 
therefore multi-elemental environment is more close to the natural systems (Lahiri and Nayak, 2002). While simulating this condition, it was found out that the PET radionuclides $66,67,69 \mathrm{Ge}$ strongly bind with albumin. The other clinically important radionuclides like ${ }^{61} \mathrm{Cu},{ }^{199-201} \mathrm{Tl}$, $197 \mathrm{~m} \mathrm{Hg}$ radionuclides bind moderately with albumin. Whereas $\mathrm{Po}, \mathrm{Bi}, \mathrm{As}$, and Se radionuclides do not at all bind or interact with albumin. These findings opened the possibility to use albumin as new ligand in radionuclidic treatment and also as biosensor (Banerjee and Lahiri, 2009).

Probably the N-terminal region of albumin, comprising of the aminoacid sequence N-Asp- Ala-His-Lys forms strong metal binding site with ${ }^{61} \mathrm{Cu}$, and ${ }^{199-201} \mathrm{Tl}$. Hg- binding by proteins in human plasma is of special interest since transportation of $\mathrm{Hg}$ in blood takes place via proteins in the system. Thus radio-labelled proteins may be developed for performing radio-diagnostic examinations as part of radiopharmaceutical applications.

Keeping the possible in vivo use in mind, we had also determined dynamic dissociation constants of the metal-albumin complexes. The Hgalbumin and Ga-albumin complexes showed lowest dissociation constant, i.e. these complexes are highly stable. Strong binding sites in bovine serum albumin (BSA) molecules coordinates with two to three imidazole nitrogen atoms and one or two carboxyl oxygen atoms. These binding sites might be responsible for formation of Hg-BSA or Ga-BSA strong complexes. Such studies on the interaction of albumin with several metal radionuclides in multi-elemental environment can be exploited in different fields of sciences including the field of nuclear medicine (Banerjee and Lahiri, 2009).

Food supplement - be careful of pb or hg poisioning

Bio-sorptions of heavy and toxic metals by three algal genera from different taxonomic groups were studied (Nayak et al., 2003). The algal genera taken for this experiment were blue green alga - Spirulina subsalsa, green alga - Oedogonium cardiacum and red alga - Catenella repens from Cyanophyceae, Chlorophyceae and Rhodophyceae families respectively.

Healthy growing algal cultures were taken for each set of experiment and were exposed to the mixture of heavy and toxic radionuclides of $\mathrm{Hg}$, $\mathrm{Tl}, \mathrm{Pb}, \mathrm{Bi}$ and $\mathrm{Po}$ at different $\mathrm{pH}$ levels. At basic $\mathrm{pH}$, Spirulina showed maximum radionuclide accumulation in the order of $\mathrm{Po}>\mathrm{Hg}>\mathrm{Bi}>\mathrm{Pb}>\mathrm{Tl}$.

The acidic $\mathrm{pH}$ inhibited the accumulation process, except for Po and $\mathrm{Hg}$. Induced acid stress conditions competitively exclude metals from binding to all cell surface ligands of Spirulina subsalsa. Oedogonium cardiacum showed very low accumulation of these toxic metals in short term exposure unlike to that of Spirulina subsalsa. As the accumulated metals were removed easily by EDTA, it implied that most of the metals 
were loosely adsorbed by cell wall surface ligands. Catenella repens showed moderate but very fast accumulation of the toxic metals at $\mathrm{pH} 7$ in the order of $\mathrm{Pb}>\mathrm{Hg}>\mathrm{Po}>\mathrm{Bi}>\mathrm{Tl}$.

In a nutshell, among these five metals, thallium is almost not accumulated by any of these algae. Accumulation of lead and mercury through absorption process was shown for Spirulina subsalsa at $\mathrm{pH} 8$, whereas that of Catenella repens was at neutral $\mathrm{pH}$. On the other hand, metal removal by adsorption process was most effective in case of Oedogonium cardiacum at acidic $\mathrm{pH}$. This study indicated that different algae have different mechanisms for metal accumulation and may sometime effectively accumulate toxic heavy metals from surrounding.

Seeds - the medium to study metal-protein interaction

Binding ability of heavy and toxic metals like $\mathrm{Hg}, \mathrm{Tl}, \mathrm{Pb}$ and $\mathrm{Bi}$ with Erythrina variegata seed protein have been investigated effectively (Datta Samanta et al., 2007). Validation was done by inter-comparing between three different approaches, trichloroacetic acid (TCA) precipitation, isoelectric precipitation and dialysis of protein after incubation with the metals. All the three approaches were in good agreement for binding of $\mathrm{Hg}, \mathrm{Tl}$ and $\mathrm{Bi} . \mathrm{Hg}$ and $\mathrm{Bi}$ showed high binding affinity with the seed protein while $\mathrm{Tl}$ showed minimum binding. However, lead showed different results with different approaches. In dialysis method lead showed high binding whereas for TCA and iso-electric precipitation binding affinity was observed much less. The solutions in both TCA and iso-electric precipitation were in highly acidic condition, which might have led to the further release of $\mathrm{Pb}$ ions after binding with proteins and as a result showed minimum interaction of $\mathrm{Pb}$ with the proteins.

A method was developed to extract gold by proteins extracted from Mimusops elengi seeds, belonging to the Sapotaceae family. Au adsorption onto the seed protein was found to be independent of $\mathrm{pH}$ of the solution. It was found that Mimusops elengi seed proteins can even extract gold as high as $50 \mathrm{ppm}$ concentration. The common name of Mimusops elengi is Bokul, which often grows wild and is also cultivated for its ornamental appearance and fragrant flowers. Whereas, the large amount of seeds is thrown away because of no such applicability. As there are very few reports on the metal protein interaction available, naturally here also the efficacy of gold extraction was estimated by four methods, viz. (a) adsorption of unbound gold using anion-exchange resin, (b) trichloroacetic acid (TCA) precipitation, (c) isoelectric precipitation and (d) dialysis of protein after incubation with gold radionuclides. It was observed that method b, c and d corroborated with each other and efficiently showed Au-binding. Whereas method a showed less binding of $\mathrm{Au}$ to protein, which may be attributed towards metal-protein linkage 
breaking tendency of the resin. Also the isoelectric point of the protein $(\mathrm{pH} 4)$ was less than the experimental $\mathrm{pH}$. That's why negatively charged proteins might have bound to the resin along with the free gold ions, preventing effective metal-protein interaction.

Hence naturally available proteins extracted from various seeds may provide a way towards environmentally benign approach in accumulating not only toxic/heavy metals but also in pre-concentrating precious metals from surroundings and acting as potential bio-reagents.

Baker's yeast - applicability in segregation and speciation studies Yeast cells of Saccharomyces cerevisiae can selectively and quantitatively

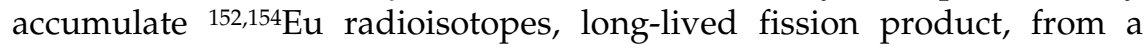
synthetic mixture of other long-lived radionuclides containing ${ }^{152,154} \mathrm{Eu}$ ${ }^{137} \mathrm{Cs}$ and ${ }^{60} \mathrm{Co}$ at neutral $\mathrm{pH}$. Different strains of baker's yeast were used and it was seen that even in the presence of 700 ppm Eu in the medium, yeast cells were able to survive and grow (Roy et al., 2008). TEM images showed that the yeast cells have accumulated Eu in the cytoplasm, which did not hamper the metabolic processes within the system either. The mechanism of metal ion uptake by yeast cells might have involved intracellular uptake and storage via active cation transport, surface binding, etc., which is not quite understandable without further researches on it. The inhibition of yeast growth due to some metals is enhanced by histidine auxotrophy and is dependent on the $\mathrm{pH}$ of the medium. However, accumulation of high amount of Eu was found to be independent of histidine auxotrophy as both $\mathrm{His}^{+}$and His- strains grew equally well under high Eu concentration. Further, it was also concluded that the mechanism of uptake of the rare earth element, Eu follows a different pathway than the transition elements, $\mathrm{Co}, \mathrm{Cu}, \mathrm{Ni}$, etc., which cause toxicity to yeast cells in the absence of the histidine biosynthetic pathway.

Two different strains of Saccharomyces cerevisiae were studied for the accumulation behaviour towards $\mathrm{Cr}$. Interestingly, it was observed that the yeast cells could accumulate $\mathrm{Cr}(\mathrm{III})$ quantitatively at basic $\mathrm{pH}(10-11)$ while no uptake was seen for $\mathrm{Cr}(\mathrm{VI})$ at the same $\mathrm{pH}$. This may be explained by the fact that $\mathrm{Cr}$ (III) initially gets adsorbed at the cell wall surface and then slowly enters the cytoplasm possibly through interactions with polysaccharides, glucoprotein and soluble peptides present at the extracellular surface. On the other hand, $\mathrm{Cr}(\mathrm{VI})$, which is more toxic than $\mathrm{Cr}$ (III) has a faster penetration into the cytoplasm but ultimately get released from the living system. Therefore, yeast cell may be used in a cost effective way to differentiate between $\mathrm{Cr}(\mathrm{III})$ and $\mathrm{Cr}(\mathrm{VI})$ (Lahiri and Roy, 2008). 
Mushrooms - scavenger of radio-cesium, the culprit in nuclear fallout

Pleurotus citrinopileatus, an edible mushroom, is a widely accepted food component. The accumulating property of this edible mushroom species towards long-lived Cs radioisotopes was studied. The mushroom species showed high bio-accumulation of radio-caesium, and interestingly about $2 / 3$ of the total accumulated caesium got accumulated in cap portion of the mushroom. Biochemical pathways of caesium accumulation was also studied and it was found out that most of the caesium was exchanged by the protein portion of mushroom. In fact, this white mushroom species, Pleurotus citrinopileatus had turned completely black after ${ }^{134} \mathrm{Cs}$ accumulation. An interesting observation was noted when these black mushrooms obtained after ${ }^{134} \mathrm{Cs}$ accumulation was allowed to reproduce up to fourth generation via tissue culture method without using any radio-caesium further, the black colour so obtained got carried on in all the next four generations. It was experimentally observed that permanent mutation took place, after accumulation of radio-caesium within the mushroom species.

To know whether radiation associated with ${ }^{134} \mathrm{Cs}$ or the Cs itself was the cause of mutation, irradiation studies were carried out with ${ }^{60} \mathrm{Co}-$ gamma rays. It was observed that the mushroom species irradiated for 18 and 24 hours by ${ }^{60} \mathrm{Co}$-gamma rays at a dose rate of $180 \mathrm{rad} / \mathrm{min}$ also turned black in colour. The black species so obtained were also grown for four successive generations, with all the generations retaining the black variety. Therefore, irradiation study revealed that the radiation associated with ${ }^{134} \mathrm{Cs}$ is responsible for occurring permanent mutation within the experimental mushroom species (Mukhopadhyay et al., 2007). Besides the chance of direct transfer of ${ }^{134} \mathrm{Cs}$ radioisotopes into the human system due to consumption of this edible mushroom variety, there also remains the possibility of indirect transfers via interconnected foodchains from other animals, which might act as the vector of ${ }^{134} \mathrm{Cs}$ to human.

Moreover, it might be assumed that the behaviour of mushroom species towards another radioisotope ${ }^{137} \mathrm{Cs}$ (an anthropogenic radionuclide with long half-life with the ability to contaminate the surrounding during any nuclear mishaps because of its lability) would be similar to that of ${ }^{134} \mathrm{Cs}$, thus making mushroom a potent bio-indicator of radioactive fall-outs.

\section{Conclusion}

It may be concluded with the fact that finally it's the time to go back to the nature in search of naturally occurring entities, which would pave a new way in green chemistry research. 
The trail of works started with utilization of orange peels from which an essential bioflavonoid, hesperidin was extracted and studied as a radio-pharmaceutical-ligand for therapeutic radioisotope, ${ }^{88} \mathrm{Zr}$. Studies on pre-concentration of precious element, $\mathrm{Au}$, was carried out in different strains of algal species under varying experimental conditions. Also attempts were made to understand the mechanism of metal bio-sorption by these algal colonies. Not only that few algal strains were capable in producing $\mathrm{Au}$ nanoparticle within their system, thus showing the prospect in nano-biotechnology. Algae were further exploited towards their behavior in separating ${ }^{201} \mathrm{Tl}$ (an important radioisotope) from the mixture of $\mathrm{Pb}, \mathrm{Hg}$ and $\mathrm{Tl}$. Moreover, these photosynthetic organisms were utilized in bio-sorption of heavy and toxic radionuclides like $\mathrm{Hg}, \mathrm{Tl}$, $\mathrm{Pb}, \mathrm{Bi}$, Po. After shifting the lime-light from algae, studies were carried out on metal-protein interaction using natural products like piperine, an alkaloid extracted from Piper nigrum fruits. Piperine and black pepper were used in accumulation of $\mathrm{Cr}$ from solution. Seed protein of Erythrina variegata was investigated for its binding affinity towards $\mathrm{Hg}$, $\mathrm{Tl}$ and $\mathrm{Bi}$.

Another animal protein, bovine serum albumin (BSA) was used as a tool in exploring its behavior in separating clinically important radioisotopes from a multi-radionuclidic mixture of $\mathrm{Cu}, \mathrm{Ga}, \mathrm{Zn}, \mathrm{Ge}, \mathrm{As}$, $\mathrm{Se}, \mathrm{Hg}, \mathrm{Tl}, \mathrm{Pb}, \mathrm{Bi}, \mathrm{Po}$, etc. Besides these, yeast cells were monitored for their ability in segregating long-lived fission product, Eu and in differentiating between trivalent $\mathrm{Cr}$ and hexavalent $\mathrm{Cr}$ in solution at a particular $\mathrm{pH}$. The last example shows mushrooms as possible option for bio-indicator towards nuclear fall-outs, because of its ability to accumulate anthropogenic radionuclide Cs.

Thus the article provides an overall glimpse of nature-based chemistry, which holds greater prospects in making our Mother Earth sustainable and less burdened with hazardous use of toxic chemical products in everyday research.

\section{Acknowledgements}

The author sincerely acknowledges the contributions of all the co-authors of the above papers. Author is grateful to Ms. Nabanita Naskar for carefully reviewing and correcting this manuscript. All the research works described here were part of two DAE-SINP five-year plan projects: 11 five year plan project TADDS (Trace Analysis: Detection, Dynamics and Speciation) and 12 five year plan project TULIP (Trace, Ultra-trace Analysis and Isotope Production). 


\section{References}

Banerjee, A.-Nayak, D.-Lahiri, S. (2007): A new method of synthesis of iron doped calcium alginate beads and determination of iron content by radiometric method. Biochem. Eng. J. 33: 260-262.

Banerjee, A.-Lahiri, S. (2009): Albumin metal interaction: a multielemental radiotracer study. J. Radioanal. Nucl. Chem. 279: 733-741.

Chakraborty, N.-Pal, R.-Ramaswami, A.-Nayak, D.-Lahiri, S. (2006): Diatom - a potential bio-accumulator of gold. J. Radioanal. Nucl. Chem. 270: 645-649.

Chakraborty, N.-Banerjee, A.-Lahiri, S.-Panda, A.-Ghosh, A. N.-Pal, R. (2009): Biorecovery of gold using cyanobacteria and an eukaryotic alga with special reference to nanogold formation - a novel phenomenon. J. Appl. Phycology. 21: $145-152$.

Datta Samanta, T.-Laskar, S.-Nayak, D.-Lahiri, S. (2007): Studies on metal-protein interactions: inter-comparison between different approaches. J. Radioanal. Nucl. Chem. 273: 323-325.

Dutta, B.-Lahiri, S.-Tomar, B. S. (2014): Separation of no-carrier-added rhenium from bulk tantalum by the sodium malonate-PEG aqueous biphasic system. Appl Radiat. Isotopes. 84: 8-12.

Ghosh, K.-Lahiri, S. (2007): Bioaccumulation of ${ }^{198} \mathrm{Au}$ by an alkaloid extracted from fruits of piper nigrum (Family: Piperaceae). J. Radioanal. Nucl. Chem. 274: 233236.

Ghosh, K.-Maiti, M.-Lahiri, S. (2013): Separation of no-carrier-added ${ }^{109} \mathrm{Cd}$ from natural silver target using RTIL 1-butyl-3-methylimidazolium hexafluorophosphate. J. Radioanal. Nucl. Chem. 298: 1049-1054.

Ghosh, K.-Naskar, N.-Choudhury, D.-Lahiri, S. (2017): Separation of no-carrieradded ${ }^{88} \mathrm{Zr}$ from proton induced bulk yttrium target by naturally synthesized hesperidin. 13 $3^{\text {th }}$ DAE-BRNS Nuclear and Radiochemistry Symposium (NUCAR-2017). KIIT University. Bhubaneswar. Odisha. India. February 6-10, 2017.

Lahiri, S.-Nayak, D. (2002): Tracer Packet: A new conception for the production of tracers of micronutrient elements. J. Radioanal. Nucl. Chem. 254: 289-292.

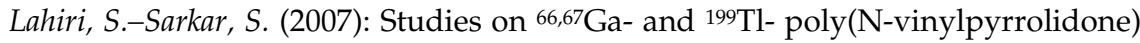
complexes. Appl. Radiat. Isotopes. 65: 309-312.

Lahiri, S.-Roy, K. (2008): Investigation on $\mathrm{pH}$ dependent uptake of $\mathrm{Cr}(\mathrm{III})$ and $\mathrm{Cr}(\mathrm{VI})$ by Baker's yeast. Indian J. Chem. Technol. 15: 417-420.

Mandal, S.-Lahiri, S. (2013): Cloud point extraction of ${ }^{99}$ Mo with Triton X-114. J. Radioanal. Nucl. Chem. 295: 1361-1364.

Mukhopadhyay, B.-Nag, M.-Laskar, S.-Lahiri, S. (2007): Accumulation of radiocesium by Pleurotus citrinopileatus species of edible mushroom. J. Radioanal. Nucl. Chem. 273: 415-418.

Nayak, D.-Lahiri, S.-Mukhopadhyay, A.-Pal, R. (2002): An eco friendly novel separation of carrier free thallium radionuclide from mercury and lead radionuclides using algae as bio-reagent. Green Chem. 4: 581-583.

Nayak, D.-Lahiri, S.-Mukhopadhyay, A.-Pal, R. (2003): Application of tracer packet technique on the studies on bio-sorption of heavy and toxic metal radionuclides by algae. J. Radioanal. Nucl. Chem. 256: 535-539. 
Nayak, D.-Nag, M.-Banerjee, S.-Pal, R.-Laskar, S.-Lahiri, S. (2006): Preconcentration of ${ }^{198} \mathrm{Au}$ in Rhizoclonium - A green alga. J. Radioanal. Nucl. Chem. 268: 337340.

Nayak, D.-Lahiri, S. (2006): Biosorption of toxic, heavy, no-carrier-added radionuclides by calcium alginate beads. J. Radioanal. Nucl. Chem. 267: 59-65.

Nayak, D.-Hazra, K. M.-Laskar, S.-Lahiri, S. (2008): Preconcentration of gold by Mimusops elengi seed proteins. J. Radioanal. Nucl. Chem. 275: 423-426.

Nayak, D.-Ghosh, K.-Lahiri, S. (2009): Studies on bio-accumulation of ${ }^{51} \mathrm{Cr}$ by Piper nigrum. J. Radioanal. Nucl. Chem. 280: 503-506.

Roy, K.-Lahiri, S. (2006): A green method for synthesis of radioactive gold nanoparticles. Green Chem. 8: 1063-1066.

Roy, K.-Sinha, P.-Lahiri, S. (2008): Immobilization of long-lived radionuclide

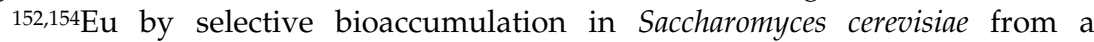

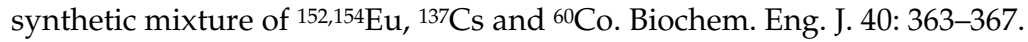

